\title{
Estimates of patient costs related with population morbidity: can indirect costs affect the results?
}

Carreras M. ${ }^{1,2, *}$, García-Goñi M. ${ }^{3}$, Ibern P. ${ }^{4}$, Coderch J. ${ }^{1}$, Vall-Llosera, L. ${ }^{1,2}$, Inoriza J.M. ${ }^{1}$

${ }^{1}$ Serveis de Salut Integrats del Baix Empordà, DAIR, Hospital 36, 17230 Palamós, Spain

${ }^{2}$ Universitat de Girona, Facultat d'Economia i Empresa, Campus de Montilivi, 17071 Girona, Spain

${ }^{3}$ Universidad Complutense de Madrid, Departamento de Economía Aplicada II, Campus de Somosaguas, 28223 Pozuelo de Alarcón, Spain

${ }^{4}$ Universitat Pompeu Fabra, Departament d'Economia, Ramon Trias Fargas 25-27, 08005 Barcelona, Spain

Tel.:+34-972-609226

* e-mail: $\underline{\text { mcarreras@ @osppal.es }}$

\begin{abstract}
A number of health economics works require patient cost estimates as a basic information input. However the accuracy of cost estimates remains in general unspecified. We propose to investigate how the allocation of indirect costs or overheads can affect the estimation of patient costs in order to allow for improvements in the analysis of patient costs estimates. Instead of focusing on the costing method, this paper proposes to highlight changes in variance explained observed when a methodology is chosen. We compare three overhead allocation methods for a specific Spanish population adjusted using the Clinical Risk Groups (CRG), and we obtain different series of full-cost group estimates. As a result, there are significant gains in the proportion of the variance explained, depending upon the methodology used. Furthermore, we find that the global amount of variation explained by risk adjustment models depends mainly on direct costs and is independent of the level of aggregation used in the classification system.
\end{abstract}

Key words Patient costs, Clinical Risk Groups, variation explained, overhead allocation

JEL classification B41, D24, I1 1 


\section{Introduction}

An accurate estimation of individual costs is essential in economic evaluation, payment systems analysis and in general, in a number of works which can be included into the health economics spectrum. Obtaining such individual or patient costs remains a complex challenge and faces numerous obstacles. The Bottom up microcosting methodology refers to the most detailed patient-specific resource consumption measurement and is considered the gold standard in the economic evaluation literature. However, its implementation is expensive and time consuming [1]. According to Wordsworth et al. [2] Bottom up microcosting is the desirable method for labour costs and other cost components that have a great impact on total costs. Tan et al. [3] showed how the selection of a different methodology (Top down microcosting or Bottom up gross costing) for labour costs and other critical cost components can produce differences in patient cost estimates in comparison with the gold standard. Clement et al. [4] investigated to what extent the selection of the costing methodology can affect the results of an economic evaluation and produce further wrong decisions. Other problems accepted by the health economics literature in the analysis of individual healthcare costs are the existence of missing data [5,6] or the application of inadequate costing methods [7].

Regardless of the methodological approach discussion, the allocation of overheads is a problematic question that requires careful attention. Some studies analyse homogeneous patient groups using only direct (or marginal) costs [8,9]. Conceptually, direct costs are directly related to the activity and in consequence are less susceptible to suffer from arbitrary allocation criteria [10]. However, the complete price of health services requires the full absorption of costs. Unfortunately, there is a general lack of consensus about the appropriate costing methodology $[10,11,12]$, until the point that some authors [13] define the overhead allocation related choices as a matter of judgement and common sense. 
The motivation for writing this article came up during the development of the research project published by Inoriza et al. [14]. The aim of the original project was to classify a specific patient population according to morbidity using the Clinical Risk Groups (CRG) model proposed by Hughes et al. [15], obtaining also their individual costs. Different costing methodologies should be used depending upon the purpose. Considering the scope of the project and the data available, a retrospective full absorption system was chosen as a suitable method. However, the implied overhead absorption and their effect in relation to the patient classification system, remained a controversial point for the research team.

In connection to such concern, this paper provides insights for filling that lack of consensus in the literature by analyzing the statistical effects caused by the overhead allocation choice. More than focusing on the costing method, our work proposes to highlight predictive changes observed when an overhead allocation methodology is chosen. Taking a specific population, we test different cost allocation methodologies obtaining different series of group averages, from which we can measure the proportion of variation of total costs explained by the risk adjustment model $\left(\mathrm{R}^{2}\right)$. The information system utilized in our estimations is the CRG model, presented in Hughes et al. [15]. We use the same concurrent (or retrospective) risk adjustment model in order to determine whether our $\mathrm{R}^{2}$ coefficients belong to a comparable range of values as other papers in the literature (above 0.42) using the same information system. Furthermore, the choice of a concurrent analysis provides a straightforward tool to observe the statistical effects caused by the overhead allocation in an isolated manner.

The properties of the CRG information system and its ability to track different groups of patients have been widely described $[15,16]$. However the relation between costing choices and the CRG predictive performance has not previously been explored. 
The rest of this paper is organised as follows. After this introduction the second section presents the data used. Section 3 describes the details on the different cost allocation methodologies. Section 4 presents the results and finally, section 5 concludes.

\section{Data}

Serveis de Salut Integrats del Baix Empordà (SSIBE) is an integrated healthcare management organisation. It is responsible for the public provision of health services - including Primary Care, Specialised Attention and Acute Hospitalisations - in the county of Baix Empordà in Catalunya (Spain). The total population in the Baix Empordà in 2005 was of 90,849 individuals.

In order to control population, morbidity and costs, SSIBE runs an integrated patient database with individual information on morbidity (procedures, diagnostic codes, discharge data, ICD9$\mathrm{CM}$ and other clinical information), services consumption (pharmaceutical and other products) and activity records. The original project objective involved classifying individuals into CRG categories using the available information on morbidity and obtaining estimates for individual costs, taking into account all the available information on health services provided by SSIBE. García-Goñi and Ibern [17] and García-Goñi et al. [22] obtained some early results on individual pharmaceutical consumption for years 2002 and 2003 with the same population.

The demographic characteristics and the risk profile of the population are shown in Table I, where we can observe how the population is almost equally distributed by gender $(50.60 \%$ are males and $49.40 \%$ are females) and $68.32 \%$ of the population belong to the category of healthy individuals.

\section{Methods}

Considering patients as the unit level objective in the analysis, we define three different cost categories: Patient or direct costs, departmental or semi-direct costs and indirect costs or 
overheads. SSIBE business lines and cost structure are shown in Table II. Only $10.98 \%$ of total costs belong to the category of direct costs assigned to patients, and $42.24 \%$ correspond to the cost of main departments. The rest of the total costs corresponds mostly to support units $29.61 \%$ and indirect costs $17.17 \%$.

The costing methodology we use combines the Bottom-Up and the Top-Down approaches described in Mogyorosy and Smith [1]. Thus, we add up direct costs of patients stemming from their related clinical records and calculate other costs from the different company departments. During year 2005, total expenses presented by the SSIBE balance sheet accounted for $45,868,690.45 €$ (excluding financial expenses, provisions, stock differences and taxes). In the next paragraphs we describe how the methodology deals with the different types of costs.

The first category of costs, direct costs (10.98\% of the total expenditures), is obtained by a Bottom Up approach as the sum of balance sheet expenses directly related to patients. They include direct costs from blood transfusions, prostheses, intermediate products, and pharmaceutical consumption.

The second category of costs, departmental costs, suppose the most important proportion of costs within the institution (71.85\%), and include costs of health services which can be charged to patients using average costs and individual patient data on use of services resources (TopDown microcosting approach). Examples of the costs recorded in this category are the number of hospital stays, laboratory tests or rehabilitation sessions.

Lastly, the third category of costs, indirect costs (supposing $17.17 \%$ of total costs) include company fixed costs as management, accounting, building amortisation, and other costs not related to the activity. Differently to direct and departmental costs, indirect costs cannot be 
assigned directly to patients based on use. Therefore, we need to assign to each patient a fair proportion of the general overheads.

The health economics literature has proposed different allocation methods. However, there is no common agreement on which of these methodologies is the best to allocate indirect costs. In this paper, we utilise and compare three different methods from the list of Bean and Hussey [11]: flat rate, output, and actual utilization. A brief description of each methodology is presented as follows:

1. Flat rate: under this methodology, overheads are shared equally among company departments. Since we have at our institution 13 different departments, general overheads are simply divided into 13 portions.

2. Output: under the output methodology, expenses are assigned proportionally to the different departments of the institution depending on the amount of services provided. Thus, general overheads are charged to each department according to the ratio: output department / global output.

3. Actual utilization: Proportional to the actual utilization of overhead costs. General overheads are divided proportionally to the ratio: department overheads / general overheads.

Table III shows the overhead absorption scheme and the monetary value attached to activity units under the three methodologies. Using the Flat rate method every department absorbs a fixed amount of 605,655.96€, while using the Output and Actual utilization methodologies the amount of overheads charged to departments depends on the activity parameter or on department overheads respectively.

We calculate estimates for the total cost associated to each individual using three different methodologies for allocating indirect costs, consequently we obtain three different vectors: 


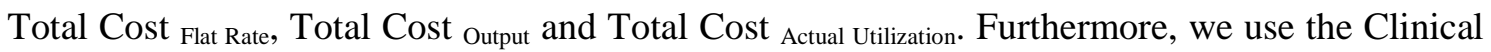
Risk Groups (CRG) classification system in order to group patients according to their morbidity, and estimate the amount of variation explained using different risk adjustment strategies for individual total health costs under the different methodologies. We present and compare every allocation cost methodology through the $\mathrm{R}^{2}$ coefficient, providing information on the proportion of variation explained by the concurrent risk adjustment model for individuals in year 2005 using morbidity information in the same year.

\section{Results}

The CRG system allows classifying individuals into mutually exclusive clinical categories attending to their health status. This classification system presents 1,099 CRG categories, which can be grouped using four different levels of aggregation: ACRG1 (441 groups), ACRG2 (176 groups), ACRG3 (46 groups) and core health status rank (9 groups). In this paper we present our results on the concurrent risk adjustment model using morbidity information grouped under the highest level of aggregation, so that average costs for each category are real costs estimates for the population belonging to that risk category during year 2005 .

Table IV presents direct average costs (Col.2) and total average costs when an absorption hypothesis is chosen (Col. 3-5). Looking at the results, Output and Actual Utilization methodologies explain a very similar amount of variation, although the $\mathrm{R}^{2}$ coefficient is slightly higher using the Output absorption method for allocating indirect costs. Total cost averages generated by health status through the risk adjustment model are very close, for output and actual utilization methods, and thus, the proportion of variance explained by the model is approximately 2 percent higher than the risk adjustment model predicting only individual direct costs. In contrast, the Flat Rate methodology differs greatly in terms of variation explained because the model tends to charge unhealthy people with large average costs. Hence, comparing the flat rate methodology with Output and Actual Utilization methods, total average costs are 
greater for status 8 and 9 (worst health status). On the other hand, using the Flat Rate absorption, the variation explained is reduced in respect to the direct cost case.

As expected, using a more detailed scale (ACRG3, ACRG2, ACRG1 or CRG) increases the proportion of variation explained by the different methodologies in the concurrent model (when current expenditures are predicted through actual CRGs), obtaining an $\mathrm{R}^{2}$ of about 0.40 . Table $\mathrm{V}$ shows the relationship between $\mathrm{R}^{2}$ and the aggregation level. We observe how the total amount of variance explained by the risk adjustment system depends mainly on the direct cost contribution, without regarding the level of aggregation. However, adding the allocation of indirect costs through the output or actual utilization methodologies makes the variation explained to increase about 2 percentage points.

\section{Discussion}

The need for accurate and quality individual cost estimates comes into the overhead allocation, in general arbitrary. Moreover, in agreement with Bean and Hussey [11] and Lucey [13], the costing literature does not offer a clear solution for the allocation of overheads, even if the objective in the analysis is the relation between costing choices and variation explained for a risk adjusted population.

A first idea, which can be drawn from our results, is that the global amount of variation explained by the Clinical Risk Groups depends mainly on direct costs. As is shown in table IV, the allocation of overheads just produces a marginal change on the variation explained in comparison with using only direct costs. This conclusion can be interpreted in line with the results of Tan et al. [3] and Wordsworth et al. [2] in the sense that focusing on critical cost components with a large impact on total costs, usually classified as direct costs, the system will produce reliable cost estimates regardless of other related specifications. 
The previous idea implies a second remarkable consideration. In spite of the variation explained depends on direct costs, using a reasonable costing methodology for allocating overheads, being the Output and Actual Utilization methodologies the most preferred, the total amount of variation explained can be increased. Table $\mathrm{V}$ shows how both methods produce a higher $\mathrm{R}^{2}$ coefficient for all levels of aggregation; CRG (1,099 groups), ACRG1 (441 groups), ACRG2 (176 groups), ACRG3 (46 groups) and core health status rank (9 groups). It is important to emphasize how the gain in variance obtained is independent of the level of aggregation used in the risk adjustment system. Whereas the global amount of variation explained increases using a more detailed scale, from health status $\left(\mathrm{R}^{2}=0.20\right)$ to $\mathrm{CRG}\left(\mathrm{R}^{2}=0.40\right)$, the gain in variance caused by the overhead allocation remains constant, about 2 percentage points.

The results obtained for the CRG aggregation level $\left(\mathrm{R}^{2}=0.40\right)$ are very similar to those obtained by Hughes et al. [15] for the concurrent model $\left(\mathrm{R}^{2}=0.42\right)$. Although the use of a concurrent analysis, without exploring the prospective implications, is a limitation of the study, such method seems to be useful in order to isolate the statistical effects produced by the overhead allocation. The alternative is the prospective approach, but some statistical distortion produced by combining information from different years would be included with certainty.

Other limitations of the study are as follows: According to Carey and Burgess [18] costing choices can be affected by many other factors not related to patient costs; the different needs that a cost system have to satisfy, the coexistence of a secondary costing system in the same company or the presence of financial incentives addressed to obtain certain results [19]. A general theoretical framework for accounting choices exists, e.g. Fields et al. [20]. However, it is lacking considering the perspective from which our study is proposed. Another limitation arises from using an unique risk assessment model, the study of the Society of Actuaries [21] evaluated 12 diagnosis and/or pharmacy based models: Adjustment Clinical Groups (ACGs) (2 versions), Chronic Illness and Disability Payment System (CDPS), Clinical Risk Groups 
(CRG), Diagnostic Cost Groups (DCGs), Episode Risk Groups (ERGs), Impact Pro, MEDai, Medicaid Rx, Pharmacy Risk Groups (PRGs), Rx Groups Risk Smart and Underwriting Model Risk Smart. To investigate whether a similar hypothesis produces similar results for other important risk assessment models would be interesting for future research works.

The CRG properties have been accurately described by works as Hughes et al. [15] or Neff et al. [16]. From a different perspective certain problems, which arise from building costs at the patient level, have been previously discussed in the costing literature. Our work combines both approaches, exploring the CRG sensibility to a specific class of costing choices, those related to overheads allocation.

Acknowledgements We wish to thank Elvira Sánchez from Serveis de Salut Integrats del Baix Empordà for providing numerous and helpful comments which helped to improve the final version of this paper. Funded by Catalan Agency for Health Technology Assessment (CAHTA), grant number: 128-01-2004 and Instituto de Salud Carlos III, grant number: PI06/90638.

\section{References}

1. Mogyorosy Z., Smith P.: The main methodological issues in costing health care services. A literature review. Centre for Health Economics, The University of York, in house publications. http://www.york.ac.uk/inst/che/pdf/rp7.pdf (2005). Accessed 09 December 2008

2. Wordsworth, S., Ludbrook, A., Caskey, F., Macleod, A.: Collecting unit cost data in multicentre studies. Creating comparable methods. Eur. J. Health Econ. 6, 38-44 (2005)

3. Tan S.S., Rutten F.F., Van Ineveld B.M., Redekop W.K., Hakkaart-van Roijen L.: Comparing methodologies for the cost estimation of hospital services. Eur. J. Health Econ. (2008). DOI: 10.1007/s10198-008-0101-x

4. Clement F., Ghali W., Donaldson C., Manns B.J.: The impact of using different costing methods on the results of an economic evaluation of cardiac care: Microcosting vs gross-costing approaches. Health Econ.(2008). DOI: 10.1002/hec.1363

5. Oostenbrink K. J., Maiwenn J.: The analysis of incomplete cost data due to dropout. Health Econ. 14, 763-776 (2005) 
6. Briggs A., Clark T., Wolstenholme J., Clarke P.: Missing... presumed at random: cost-analysis of incomplete data. Health Econ. 12, 377-392 (2003)

7. Graves N., Walker D., Raine R., Hutchings A., Roberts J.A..: Cost data for individual patients included in clinical studies: no amount of statistical analysis can compensate for inadequate costing methods. Health Econ. 11, 735-739 (2002)

8. Ibern P. La información de costes por GRD: Resultados de una experiencia. In: Los grupos relacionados con el diagnóstico (GRD), experiencia y perspectivas de utilización, pp. 221-239. Masson, Barcelona (1991)

9. Maciejewski M., Chapko M., Hedeen A., Fortney J.: VA Community-Based Outpatient Clinics: Cost Performance Measures. Med. Care 40(7), 587-595 (2002)

10. Johnson T., Kaplan R.: Rise and Fall of management accounting. Manag. Account. 68(7), 22-30 (1987)

11. Bean J., Hussey L.: Costing and pricing public cost services. Essential skills for the public sector. HB Publications, London (1996)

12. Young D.W.: Management accounting in health care organisations. Jossey-Bass, a Wiley Company (2003)

13. Lucey T.: Costing. Sixth edition. Thompson Learning, United Kingdom (2002)

14. Inoriza J.M., Coderch J., Carreras M., Vall.Llosera L., Ibern P., García-Goñi M., Lisbona J.M.: La medida de la morbilidad poblacional en una organización sanitaria integrada. Gac. Sanit. (2008) In press

15. Hughes J.S., Averill R.F., Eisenhandler J., Goldfield N.I., Muldoon J., Neff J.M., Gay J.: Clinical Risk Groups (CRGs): A Classification System for Risk-Adjusted Capitation-Based Payment and Health Care Management. Med. Care 42(1), 81-90 (2008)

16. Neff J.M., Sharp V.L., Muldoon J., Graham J., Myers K.: Profile of Medical Charges for Children by Health Status and Severity Level in a Washington State Health Plan. Health Serv. Res. 39(1), 73-90 (2004)

17. García-Goñi M., Ibern P.: Predictability of drug expenditures: an application using morbidity data. Health Econ. 17(1), 119-126 (2008)

18. Carey K., Burgess J.: Hospital Costing: Experience from the VHA. Financial Account. and Manag. 16(4), 289-308 (2000)

19. Robbins W. A., Turpin R., Polinski P.: Economic Incentives and Accounting Choice Strategy by Nonprofit Hospitals. Financial Account. and Manag. 9(3), 159-175 (1993)

20. Fields T., Lys T., Vincent L.: Empirical research on accounting choice. J. of Account. and Econ. 31, 255-307 (2000)

21. Winkelman R., Mehmud S.: A Comparative Analysis of Claims-Based Tools for Health Risk Assessment. Society of Actuaries. http://www.soa.org/research/health/hlth-risk-assement.aspx (2007). Accessed 09 December 2008

22. García-Goñi M., Ibern P., Inoriza J.M.: Hybrid risk adjustment for pharmaceutical benefits. Eur. J. Health Econ. (2008). DOI: 10.1007/s10198-008-0133-2 
Table I. Demographic characteristics of the population

Demographic characteristics

Female

$49.40 \%$

Male

$50.60 \%$

Age (mean)

40.45

$0-14$

$14.99 \%$

$15-29$

$19.79 \%$

$30-44$

$25.28 \%$

45-64

$21.89 \%$

65-79

$11.97 \%$

80 or older

$6.07 \%$

Aggregated clinical risk group categories of patients

Healthy

$68.32 \%$

History of significant acute disease

$9.17 \%$

Single minor chronic disease

$5.72 \%$

Minor chronic disease in multiple organ system

$0.85 \%$

Single dominant or moderate chronic disease

$10.74 \%$

Disease in chronic multiple organ systems

$4.34 \%$

Dominant chronic disease in three or more organ systems

Dominant and metastatic malignancies

$0.33 \%$

Catastrophic conditions

$0.19 \%$

Note: $N=90,849$ individuals. 
Table II. Company cost structure

\begin{tabular}{|c|c|c|c|}
\hline & Direct costs & Indirect costs & $\%$ \\
\hline \multicolumn{4}{|l|}{ Direct costs } \\
\hline Patient costs & $5,034,972.65$ & --- & $10.98 \%$ \\
\hline \multicolumn{4}{|c|}{ Departmental costs. Main departments } \\
\hline Primary Care & $6,224,866.43$ & $4,535,879.18$ & $23.46 \%$ \\
\hline Inpatient Hospital & $3,991,965.29$ & $1,264,058.73$ & $11.46 \%$ \\
\hline Outpatient Hospital & $2,095,646.09$ & $1,262,709.28$ & $7.32 \%$ \\
\hline \multicolumn{4}{|c|}{ Departmental costs. Support departments } \\
\hline Emergencies & $4,277,816.11$ & $61,174.21$ & $9.46 \%$ \\
\hline Surgical Area & $3,352,119.21$ & $226,200.19$ & $7.80 \%$ \\
\hline Laboratory & $1,775,725.10$ & $96,210.47$ & $4.08 \%$ \\
\hline Radiology & $1,153,040.34$ & $180,853.96$ & $2.91 \%$ \\
\hline Haemodialysis & $846,107.44$ & $70,060.00$ & $2.00 \%$ \\
\hline Rehabilitation & $510,443.86$ & $18,529.34$ & $1.15 \%$ \\
\hline MA Surgery - Day Hospital & $501,056.34$ & $15,328.61$ & $1.13 \%$ \\
\hline Hyperbaric Medicine & $234,936.46$ & $7,256.01$ & $0.53 \%$ \\
\hline Short stay units & $143,922.23$ & $4,984.68$ & $0.32 \%$ \\
\hline \multicolumn{4}{|c|}{ Departmental costs. Other departments } \\
\hline Podology, Sports Medicine & $105,286.22$ & $4,014.58$ & $0.24 \%$ \\
\hline \multicolumn{4}{|l|}{ Indirect costs } \\
\hline General overheads & --- & $7,873,527.43$ & $17.17 \%$ \\
\hline Total costs & $30,247,903.77$ & $15,620,786.67$ & $100.00 \%$ \\
\hline
\end{tabular}


Table III. Department overhead absorption and monetary value attached to activity units

\begin{tabular}{|c|c|c|c|c|c|c|c|c|}
\hline Departments & Unit & Activity & \multicolumn{2}{|c|}{ Flat rate } & \multicolumn{2}{|c|}{ Output } & \multicolumn{2}{|c|}{ Actual utilization } \\
\hline Main departments & & & Absorption & Unit value & Absorption & Unit value & Absorption & Unit value \\
\hline Primary Care & Visit & 612,609 & $605,655.96$ & 0.99 & $4,271,903.80$ & 6.97 & $4,609,806.90$ & 7.52 \\
\hline Inpatient Hospital & Stay & 33,224 & $605,655.96$ & 18.23 & $231,680.78$ & 6.97 & $1,284,660.91$ & 38.67 \\
\hline Outpatient Hospital & Visit & 132,501 & $605,655.96$ & 4.57 & $923,968.67$ & 6.97 & $1,283,289.46$ & 9.69 \\
\hline \multicolumn{9}{|l|}{ Support departments } \\
\hline Emergencies & Emergency & 52,940 & $605,655.96$ & 11.44 & $369,166.28$ & 6.97 & $62,171.26$ & 1.17 \\
\hline Surgical Area & Intervention & 4,522 & $605,655.96$ & 133.94 & $31,533.24$ & 6.97 & $229,886.90$ & 50.84 \\
\hline Laboratory & Test & 126,821 & $605,655.96$ & 4.78 & $884,360.35$ & 6.97 & $97,778.55$ & 0.77 \\
\hline Radiology & Image & 73,506 & $605,655.96$ & 8.24 & $512,579.09$ & 6.97 & $183,801.60$ & 2.50 \\
\hline Haemodialysis & Session & 6,851 & $605,655.96$ & 88.40 & $47,774.05$ & 6.97 & $71,201.87$ & 10.39 \\
\hline Rehabilitation & Session & 73,181 & $605,655.96$ & 8.28 & $510,312.76$ & 6.97 & $18,831.34$ & 0.26 \\
\hline MA Surgery - Day Hospital & Session & 6,769 & $605,655.96$ & 89.47 & $47,202.24$ & 6.97 & $15,578.44$ & 2.30 \\
\hline Hyperbaric Medicine & Session & 621 & $605,655.96$ & 975.29 & $4,330.42$ & 6.97 & $7,374.27$ & 11.87 \\
\hline Short stay units & Stay & 777 & $605,655.96$ & 779.48 & $5,418.25$ & 6.97 & $5,065.92$ & 6.52 \\
\hline \multicolumn{9}{|l|}{ Other departments } \\
\hline Podology, Sports Medicine & Visit & 4,775 & $605,655.96$ & 126.84 & $33,297.49$ & 6.97 & $4,080.01$ & 0.85 \\
\hline Total & & $1,129,097$ & $7,873,527.43$ & --- & $7,873,527.43$ & --- & $7,873,527.43$ & --- \\
\hline
\end{tabular}


Table IV. Average costs by core health status

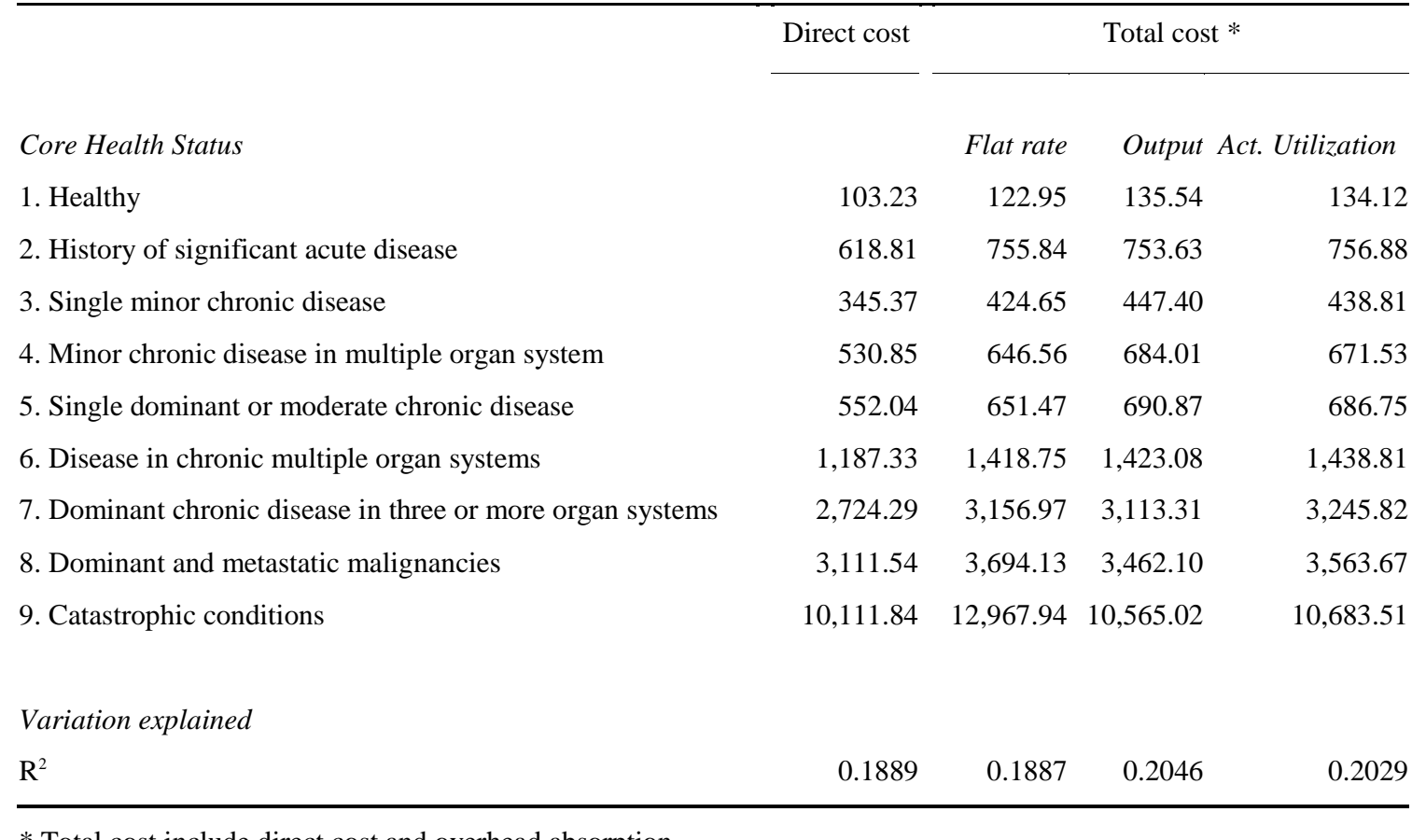

* Total cost include direct cost and overhead absorption 
Table V. Variation explained by aggregation level for the CRG concurrent model

\begin{tabular}{lcccc}
\hline & \multicolumn{5}{c}{$\mathrm{R}^{2}$} \\
\cline { 2 - 5 } & Direct cost & Flat Rate & Output & Act. Utilization \\
\hline Aggregation Level & & & & \\
Health status & 0.1889 & 0.1877 & 0.2046 & 0.2029 \\
ACRG3 & 0.2684 & 0.2796 & 0.2896 & 0.2905 \\
ACRG2 & 0.3262 & 0.3526 & 0.3469 & 0.3477 \\
ACRG1 & 0.3458 & 0.3692 & 0.3668 & 0.3686 \\
CRG & 0.3784 & 0.3977 & 0.3989 & 0.4021 \\
\hline
\end{tabular}

